\title{
Loss of autonoetic awareness of recent autobiographical episodes and accelerated long-term forgetting in a patient with previously unrecognized glutamic acid decarboxylase antibody related limbic encephalitis
}

OPEN ACCESS

Edited by:

Nico Melzer,

University of Münster, Germany

Reviewed by:

Hubertus Lohmann,

University of Münster, Germany

Albrecht Kunze,

University Hospital Jena, Germany

*Correspondence:

Juri-Alexander Witt,

Department of Epileptology, University

of Bonn, Sigmund-Freud-Str. 25,

Bonn 53105, Germany

juri-alexander.witt@ukb.uni-bonn.de

Specialty section: This article was submitted to Epilepsy, a section of the journal Frontiers in Neurology

Received: 15 April 2015 Accepted: 19 May 2015

Published: 09 June 2015

Citation:

Witt J-A, Vogt VL, Widman G, Langen K-J, Elger CE and Helmstaedter C (2015) Loss of

autonoetic awareness of recent

autobiographical episodes and accelerated long-term forgetting in a patient with previously unrecognized glutamic acid decarboxylase antibody related limbic encephalitis.

Front. Neurol. 6:130.

doi: 10.3389/fneur.2015.00130

\section{Juri-Alexander Witt ${ }^{1 *}$, Viola Lara Vogt ${ }^{1}$, Guido Widman ${ }^{1}$, Karl-Josef Langen ${ }^{2}$, Christian Erich Elger ${ }^{1}$ and Christoph Helmstaedter ${ }^{1}$}

\section{Department of Epileptology, University of Bonn, Bonn, Germany, ${ }^{2}$ Institute of Neuroscience and Medicine, Forschungszentrum} Jülich, Jülich, Germany

We describe a 35-year-old male patient presenting with depressed mood and emotional instability, who complained about severe anterograde and retrograde memory deficits characterized by accelerated long-term forgetting and loss of autonoetic awareness regarding autobiographical memories of the last 3 years. Months before he had experienced two breakdowns of unknown etiology giving rise to the differential diagnosis of epileptic seizures after various practitioners and clinics had suggested different etiologies such as a psychosomatic condition, burnout, depression, or dissociative amnesia. Neuropsychological assessment indicated selectively impaired figural memory performance. Extended diagnostics confirmed accelerated forgetting of previously learned and retrievable verbal material. Structural imaging showed bilateral swelling and signal alterations of temporomesial structures (left $>$ right). Video-EEG monitoring revealed a left temporal epileptic focus and subclincal seizure, but no overt seizures. Antibody tests in serum and liquor were positive for glutamic acid decarboxylase antibodies. These findings led to the diagnosis of glutamic acid decarboxylase antibody related limbic encephalitis. Monthly steroid pulses over 6 months led to recovery of subjective memory and to intermediate improvement but subsequent worsening of objective memory performance. During the course of treatment, the patient reported de novo paroxysmal non-responsive states. Thus, antiepileptic treatment was started and the patient finally became seizure free. At the last visit, vocational reintegration was successfully in progress. In conclusion, amygdala swelling, retrograde biographic memory impairment, accelerated long-term forgetting, and emotional instability may serve as indicators of limbic encephalitis, even in the absence of overt epileptic seizures. The monitoring of such patients calls for a standardized and concerted multilevel diagnostic approach with repeated assessments.

Keywords: autoimmune encephalitis, autoantibody, accelerated forgetting, memory, cognition, neuropsychology, epilepsy, amygdala 


\section{Introduction}

Limbic encephalitis defines a clinical syndrome caused by autoimmune-mediated structural-morphological and metabolic changes primarily affecting mesiotemporal structures $(1,2)$. Thus, clinical symptoms can comprise episodic memory impairment, affective disturbances, and/or temporal lobe seizures. Paraneoplastic and non-paraneoplastic subforms of limbic encephalitis are differentiated, and meanwhile several autoantibodies underlying this autoimmune process have been identified (3-5). Autoantibodies can be directed against neuronal cell surface antigens or against intracellular neuronal antigens. Herewith, we report a patient with previously unrecognized glutamic acid decarboxylase (GAD) antibody related limbic encephalitis primarily characterized by severe neuropsychological impairments. Antibodies to the $65 \mathrm{kDa}$ isoform of the intracellular enzyme GAD define a form of non-paraneoplastic limbic encephalitis (6).

\section{Case Report}

The 35-year-old male patient consulted our outpatient department in February 2012, after having experienced a second episode of a breakdown with confusion and severe but unspecified headache. A first episode happened in September 2011, the second in January 2012. In the morning after the first episode, he realized a retrograde episodic memory loss spanning the preceding 3 years. For instance, he only had shadowy memories of a recent travel abroad without any emotional attachment or autonoetic awareness. The same was true for usually highly emotional incidents such as a wedding and a bereavement. In addition, as a teacher, he was no longer aware of the content of his last given lessons, but he was able to recall his pupils' names and faces. Finally, anterograde memory problems were complained resembling the phenomenon of accelerated long-term forgetting, i.e., new information can be successfully learned and recalled, but after few days respective memory recall is no longer possible.

Since the first episode and before coming to our department, the patient went to various practitioners and clinics suggesting different etiologies such as a psychosomatic condition, a burnout, a depression, or dissociative amnesia. He presented with depressed mood, significant emotional instability, and bewilderment. He felt that he was not capable to work in this condition. The patient suffered from diabetes mellitus type 1 and this had also been considered as a possible source of his problems. It is important to note that there were no overt epileptic seizures at that time, but the patient reported brief aura-like states with an ascending feeling and an autoscopic experience (about twice per month), which he had interpreted as possibly resulting from hypoglycemia in the context of his diabetes.

The treating physician and the neuropsychologist who talked to the patient at our outpatient clinic suspected limbic encephalitis, and in the same month the patient underwent (differential) diagnostics as an in-patient. Figure 1 gives an graphical overview of the chronology of diagnostics and treatments. Complementary Table 1 summarizes the major findings.

The initial standardized neuropsychological assessment (February 2012) in the ambidextrous patient pointed to an impairment of figural learning (DCS-R, (7), whereas verbal learning and memory including delayed free recall after $30 \mathrm{~min}$. (VLMT) (8) was normal, the learning performance even above average. Average results were achieved for attention and executive functions (EpiTrack ${ }^{\circledR}$ ) (9). Based on this neuropsychological profile, a right temporal lobe dysfunction was deduced assuming typical left hemispheric language dominance $(7,10,11)$. However, because of ambidexterity and left-hemispheric accentuation of the temporomesial structural abnormalities, language dominance was assessed by functional MRI (12) and functional transcranial Doppler sonography (13) concordantly indicating typical left hemispheric language dominance. In order to clarify the mismatch of subjective memory complaints and testing of verbal learning and memory and to address the subjective complaints of accelerated long-term forgetting, verbal memory material presented during the neuropsychological evaluation was requested again (free recall and recognition) 1 week later [cf. Ref. (14)]. Memory performance after this extended retention interval was severely impaired (Figure 2). In this way, the respective subjective complaints could be objectified.

The Beck depression inventory I indicated mildly depressed mood (13 points; cutoff $>10$ ).

Structural imaging showed a bilateral swelling with signal alterations of the temporomesial structures more prominent within the left hemisphere (Figure 3). MRI volumetry confirmed a significantly increased volume of the left amygdala as compared to normative data (Figure 3).

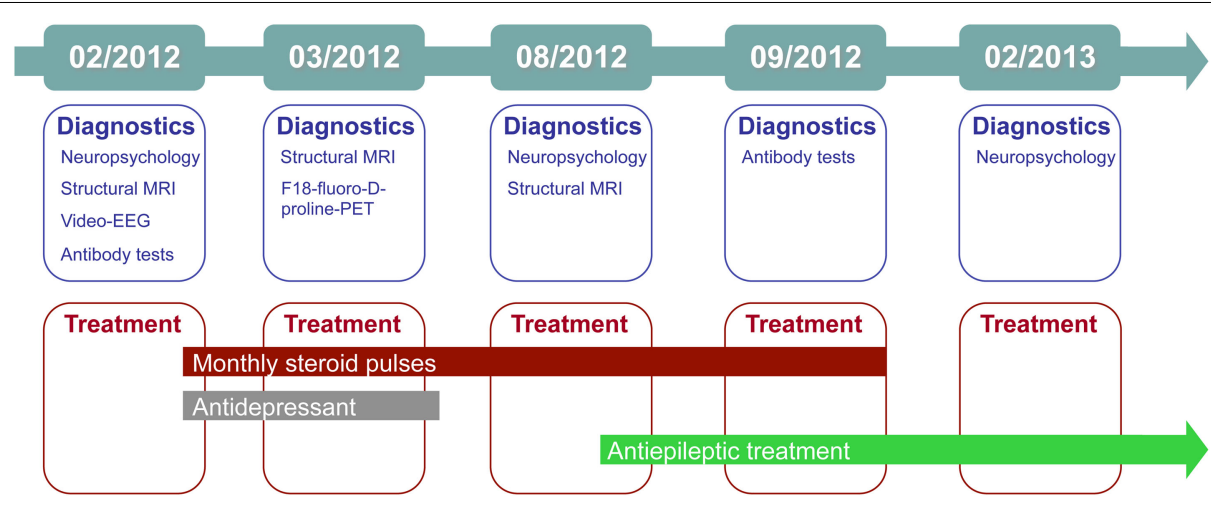

FIGURE 1 | Graphical overview of the chronology of diagnostics and treatments. 
TABLE 1 | Chronology and major findings in the course of the presented patient with glutamic acid decarboxylase antibody related limbic encephalitis.

\begin{tabular}{|c|c|c|c|c|c|c|c|}
\hline & $\begin{array}{c}\text { September } \\
2011\end{array}$ & $\begin{array}{c}\text { January } \\
2012\end{array}$ & $\begin{array}{l}\text { February } \\
2012\end{array}$ & $\begin{array}{l}\text { April and } \\
\text { May } 2012\end{array}$ & $\begin{array}{l}\text { August } \\
2012\end{array}$ & $\begin{array}{c}\text { September } \\
2012\end{array}$ & $\begin{array}{c}\text { September } \\
2013\end{array}$ \\
\hline Comment & Breakdown & Breakdown & $\begin{array}{l}\text { First outpatient contact } \\
\text { with subsequent } \\
\text { inpatient evaluation }\end{array}$ & - & - & - & $\begin{array}{l}\text { Final contact; } \\
\text { stepwise vocational } \\
\text { reintegration in } \\
\text { progress }\end{array}$ \\
\hline $\begin{array}{l}\text { Structural- } \\
\text { morphological } \\
\text { findings }\end{array}$ & - & - & $\begin{array}{l}\text { Bilateral } \\
\text { swelling }+ \text { signal } \\
\text { alterations of } \\
\text { temporomesial } \\
\text { structures (left }>\text { right) }\end{array}$ & - & $\begin{array}{l}\text { Hippocampal volumes } \\
\text { decreased within the } \\
\text { normal range, } \\
\text { enlargement of left } \\
\text { amygdala remained }\end{array}$ & - & - \\
\hline $\begin{array}{l}\text { Objective } \\
\text { memory }\end{array}$ & - & - & $\begin{array}{l}\text { Verbal: average ( } 30 \text { min } \\
\text { retention), but ALF } \\
\text { ( } 1 \text { week retention); } \\
\text { figural: impaired }\end{array}$ & - & $\begin{array}{l}\text { Improvement } \\
\text { Verbal: good } \\
\text { Figural: borderline }\end{array}$ & - & $\begin{array}{l}\text { Verbal: borderline } \\
\text { Figural: impaired }\end{array}$ \\
\hline $\begin{array}{l}\text { Subjective } \\
\text { memory }\end{array}$ & $\begin{array}{l}\text { Anterograde } \\
\text { and } \\
\text { retrograde } \\
\text { deficits }\end{array}$ & $\begin{array}{l}\text { Anterograde } \\
\text { and } \\
\text { retrograde } \\
\text { deficits }\end{array}$ & $\begin{array}{l}\text { Anterograde and } \\
\text { retrograde deficits }\end{array}$ & $\begin{array}{l}\text { Clear } \\
\text { anterograde } \\
\text { memory } \\
\text { improvement }\end{array}$ & $\begin{array}{l}\text { Nearly premorbid level } \\
\text { regarding anterograde } \\
\text { memory }\end{array}$ & Memory decline & $\begin{array}{l}\text { Memory } \\
\text { improvement; partial } \\
\text { recovery of } \\
\text { biographical memory }\end{array}$ \\
\hline Mood & $?$ & $?$ & $\begin{array}{l}\text { Depressed mood } \\
\text { Emotional instability }\end{array}$ & - & Depressed mood & & Improved mood \\
\hline $\begin{array}{l}\text { Seizures and } \\
\text { epileptiform } \\
\text { discharges }\end{array}$ & $?$ & $?$ & $\begin{array}{l}\text { Left temporal focus in } \\
\text { video-EEG }\end{array}$ & - & $\begin{array}{l}\text { De novo } \\
\text { non-responsive states }\end{array}$ & $\begin{array}{l}\text { Two episodes of a } \\
\text { strange feeling } \\
\text { with subsequent } \\
\text { memory loss }\end{array}$ & $\begin{array}{l}\text { Unspecific feelings } \\
\text { (aura?), no overt } \\
\text { seizures }\end{array}$ \\
\hline Titers & - & - & $\begin{array}{l}\text { liquor (IFT): GAD 65: } \\
1: 3.2 \text { serum } \\
\text { (ELISA):GAD } \\
65:>2.000 \mathrm{IE} / \mathrm{ml}\end{array}$ & & & $\begin{array}{l}\text { Liquor (IFT):GAD } \\
65: 1: 3.2 \text { serum } \\
\text { (ELISA):GAD } \\
65:>2.000 \mathrm{IE} / \mathrm{ml}\end{array}$ & - \\
\hline Treatment & - & - & $\begin{array}{l}\text { Monthly steroid-pulses; } \\
\text { antidepressant } \\
\text { treatment }\end{array}$ & $\begin{array}{l}\text { Monthly } \\
\text { steroid- } \\
\text { pulses }\end{array}$ & $\begin{array}{l}\text { Monthly steroid-pulses; } \\
\text { antiepileptic treatment }\end{array}$ & $\begin{array}{l}\text { Last steroid- } \\
\text { pulse; antiepileptic } \\
\text { treatment }\end{array}$ & $\begin{array}{l}\text { Antiepileptic } \\
\text { treatment }\end{array}$ \\
\hline
\end{tabular}

ALF, accelerated long-term forgetting; GAD, glutamic acid decarboxylase.

During video-EEG over five consecutive days, a specific left temporal focus and a subclinical seizure following hyperventilation were recorded (Figure 4).

Laboratory tests revealed oligoclonal bands and no evidence of blood-brain barrier disruption. Serum and liquor antibody tests were negative for amphiphsyin, CV2, Ma/Ta, Ri, Yo, and Hu, MAG, Tr, Myelin, Aquaporin, Glycin, NMDA, AMPA, GABAb, VGKC (incl. LGI1 and CASPR2), but positive for GAD 65 (liquor: 1:3,2 [IFT]) (serum:>2.000 IE/ml [ELISA]) and 67 (serum: 1:1.000 [IFT]) and varicella-zoster virus (VZV-IgG: serum: $3.600 \mathrm{mIE} / \mathrm{ml}$ [ELISA]). HHV6-IFT IgG und IgM were positive in serum [IFT].

Thorough tumor diagnostics were negative.

The overall findings led to the diagnosis of GAD antibody related limbic encephalitis and therefore immunotherapy was initiated comprising monthly steroid-pulse-therapy from February to September 2012 (1000 mg methylprednisolone i.v. on five consecutive days per cycle).

In March 2012, F18-fluoro-D-proline-positron emission tomography (PET) was performed in search of biomarkers of an active inflammatory process. Studies had revealed that Cis-4-[F18]fluoro-D-proline uptake is associated with secondary neurodegeneration in the presence of brain tumors and after cortical infarction $(15,16)$. However, in the present case, an abnormal tracer accumulation was not observed (Figure 5). In contrast to structural imaging in February, the structural MRI at the time of the PET (for the purpose of image fusing) showed bitemporal hyperintensities now clearly more marked within the right hemisphere (Figure 5).

In August, the patient reported de novo seizure-like nonresponsive states. Therefore, antiepileptic treatment with lamotrigine (target dose $200 \mathrm{mg} / \mathrm{d}$ ) was initiated. Repeated structural MRI with subsequent volumetry still showed an enlargement of the left amygdala, while the hippocampal volumes decreased but remained within the normal range of healthy subjects. The neuropsychological follow-up demonstrated significant improvement in figural memory performance when taking practice corrected reliable change indices as the reference for judging intraindividual change $(p<0.1)$ (Figure 6: first follow-up 21 August, 2012).

Verbal learning and memory improved as well, but taking into consideration the already good performance at baseline a ceiling effect was evident. Attention and executive functions were stable and remained unimpaired. The patient reported that, after the third cycle of steroid-pulse therapy in April, his memory improved to a nearly premorbid level. Episodes during the preceding month could be remembered without difficulty and there was no more self-perceived accelerated long-term forgetting. However, the Beck depression inventory still indicated depressed mood. 


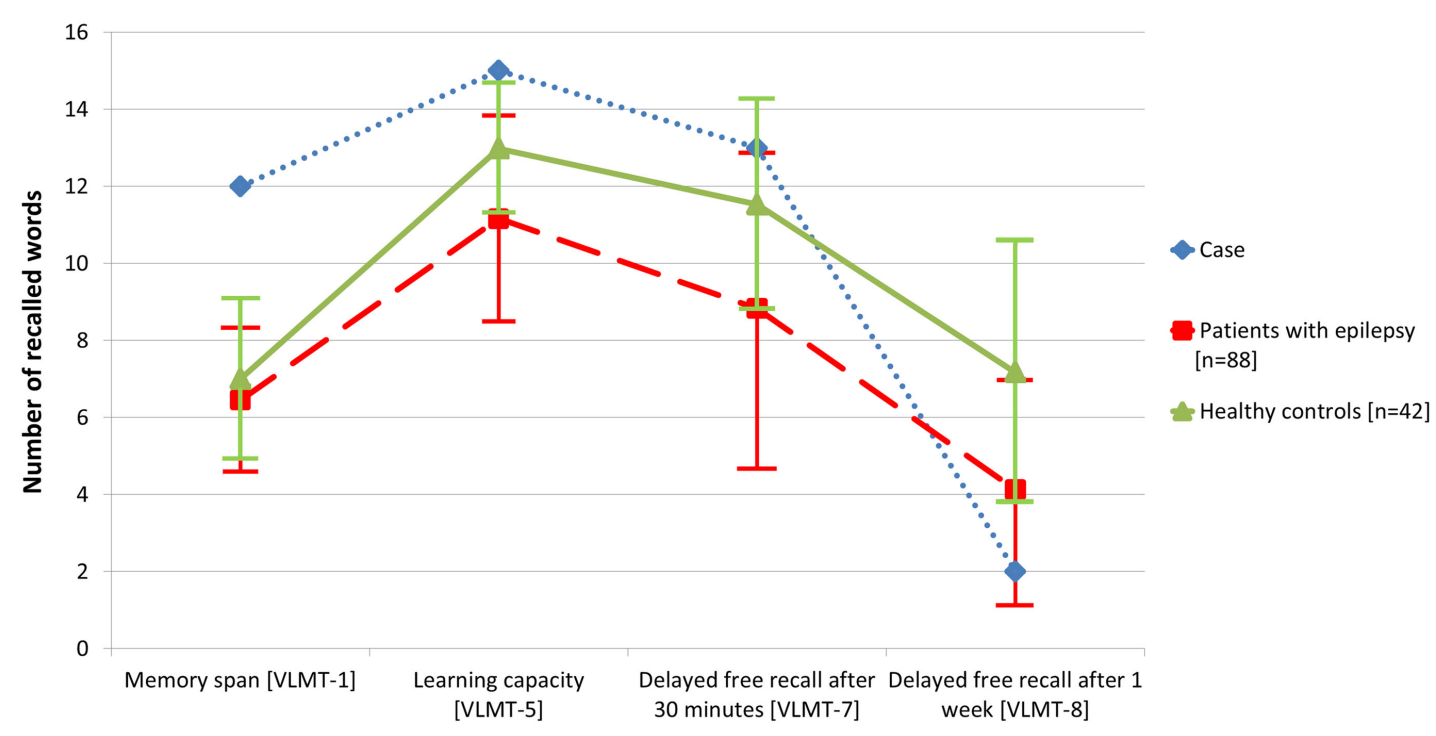

Verbal learning and memory performance

FIGURE 2 | Compared with data from healthy controls $(n=42)$, objective memory assessment in the presented patient with glutamic acid decarboxylase antibody related limbic encephalitis (February 2012) revealed normal to above average performance with regard to verbal learning and free recall after $30 \mathrm{~min}$, but accelerated long-term forgetting after $\mathbf{1}$ week. For comparison, the figure also illustrates the memory performance of a random sample of patients with epilepsy $(n=88)$.
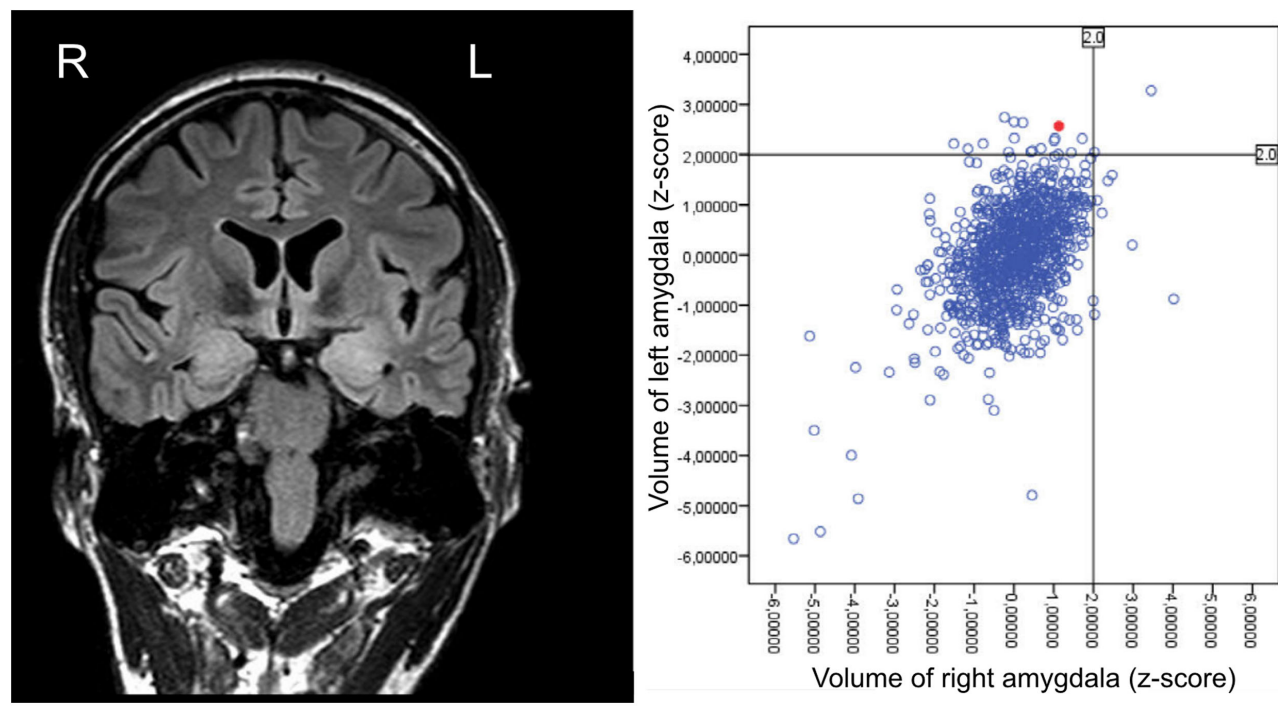

\section{Pool}

Controls

FIGURE 3 | Structural MRI (performed in February 2012) showing bilateral swelling with signal alterations of the temporomesial structures more prominent on the left hemisphere, and respective volumetric results revealing enlargement of the left amygdala as compared to healthy controls

In September, before the sixth and last cycle of steroid-pulse therapy, the patient reported two episodes of a strange feeling with subsequent memory loss. Subjectively, memory performance had become worse. After the last cycle of immunotherapy, the patient was released in a good overall condition. No need for further immunotherapy was concluded.

One year after the first contact, in February 2013, the patient still reported infrequent episodes of unspecific feelings without loss of consciousness. The objective memory assessment now showed a significant decrease in verbal memory capacity and a borderline performance in figural memory (Figure 6: second follow-up 19 February, 2013). In contrast, subjective memory performance improved including a partial recovery of autobiographical memory and of mood as indicated by the depression inventory (BDI I: 6 points; cutoff: >10). Stepwise vocational reintegration (status at that time $75 \%$ ) was successfully in progress. 


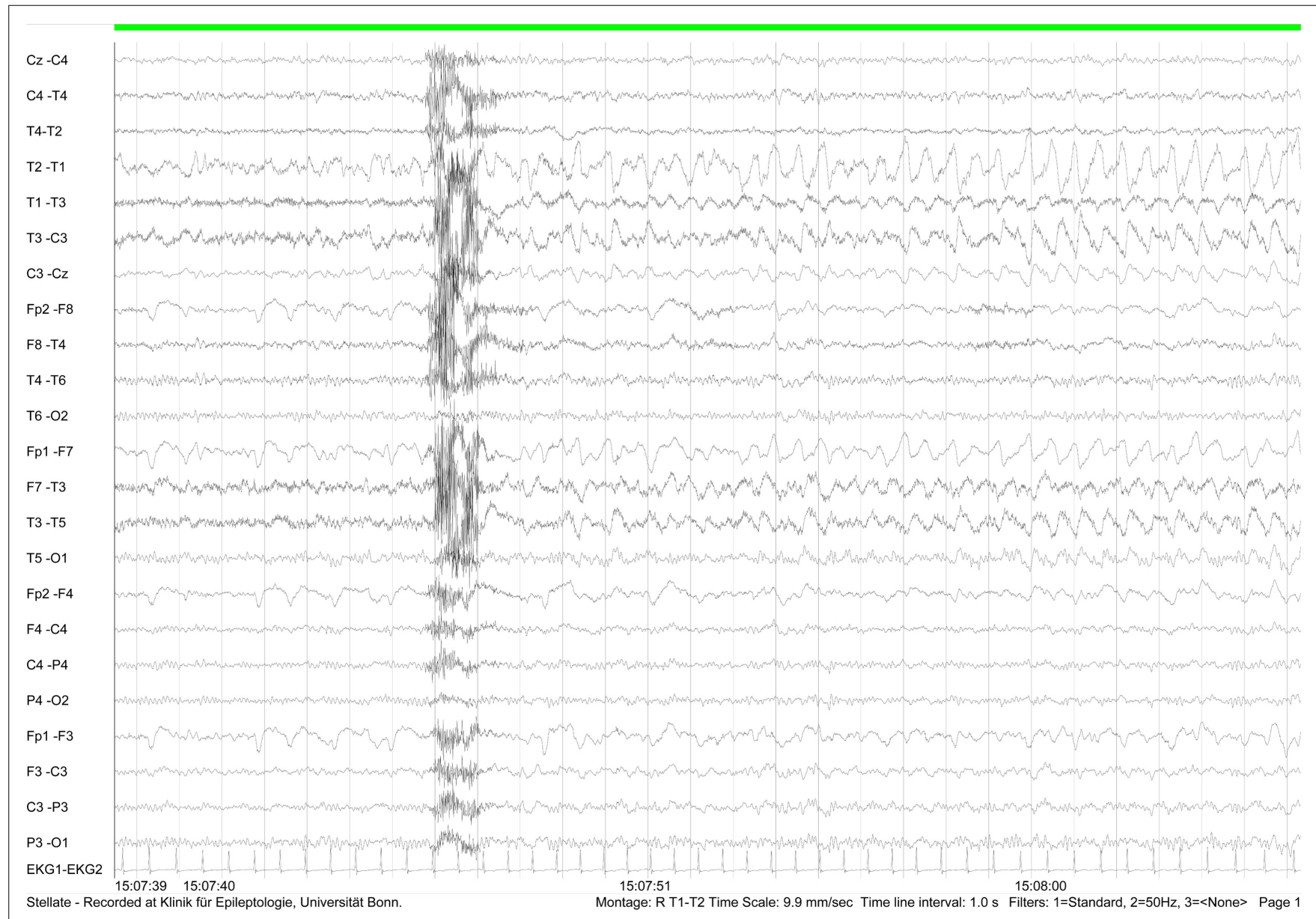

Stellate - Recorded at Klinik für Epileptologie, Universität Bonn.

Montage: R T1-T2 Time Scale: $9.9 \mathrm{~mm} / \mathrm{sec}$ Time line interval: 1.0 s Filters: $1=$ Standard, 2=50Hz, 3=<None> Page 1

FIGURE 4 | EEG recording (February 2012) showing subclinical left frontotemporal seizure following hyperventilation.

\section{Discussion}

The presented case report of a patient with previously unrecognized glutamic acid decarboxylase antibody related limbic encephalitis is noteworthy in several ways: first of all, the neuropsychological and psychiatric disturbances putatively preceded the first overt epileptic seizure, assuming that the breakdowns of unknown etiology had probably not been of epileptic origin. For some months, the patient underwent some sort of odyssey visiting various practitioners and clinics entailing different diagnoses ranging from burnout to dissociative amnesia. Overt epileptic seizures first manifested in the course of the immunotherapy. The neuropsychological memory profile was exceptional both in regard to anterograde and retrograde memory functions: retrograde memory deficits were characterized by loss of emotional attachment and autonoetic awareness of autobiographical memories spanning the preceding 3 years. Even a wedding and bereavement could not be ecphorized. There was a lack of an emotional attachment, the usually highly emotional events could only be remembered in a shadowy way and primarily on a semantic level. The affection of the left amygdala as revealed by structural imaging may have contributed to or even caused this reversible autobiographical memory impairment, since the amygdala is part of the basolateral limbic circuit which is relevant for emotional valence of memories (17). Unfortunately, only two structural MRIs have been conducted during the course of the disease both showing a swelling of the left amygdala which was confirmed by volumetry. However, at the final visit when partial recovery of the autobiographical memories was reported, no structural imaging was performed again to examine whether the swelling of the amygdala was regressive or even vanished. A recent longitudinal study by Wagner et al. described distinct volumetric and clinical courses in limbic encephalitis (18). Patients with GAD antibodies initially exhibited greater amygdala volumes with subsequent normalization in the course of treatment. Few studies reported retrograde memory deficits in limbic encephalitis with mostly bilateral affection of the mesiotemporal structures (19-23), but to our knowledge - none of the investigated patients exhibited this specific loss of emotional attachment and autonoetic awareness. Moreover, none of the patients suffered from glutamic acid decarboxylase antibody related limbic encephalitis.

Besides his psychiatric problems, a major reason for the patient's inability to keep working as a teacher was his severe anterograde memory impairment. Newly encoded episodes, e.g., the content of his last given lessons, could be remembered up to 3 days, but were then lost or no longer accessible. In a case report, 


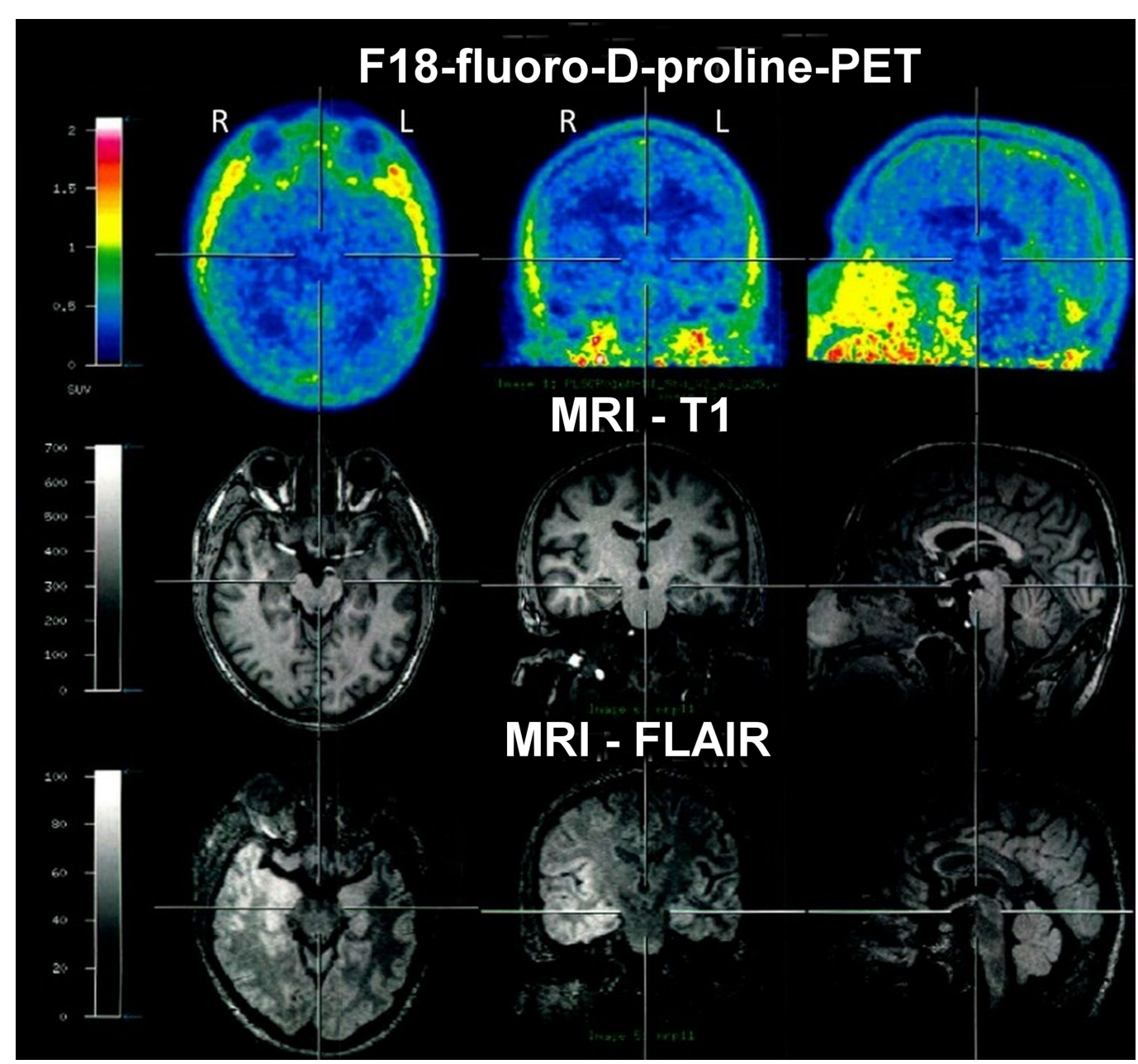

FIGURE 5 | F18-fluoro-D-proline-positron emission tomography (PET) in March 2012 showed no abnormal tracer accumulation. Structural MRI again showed bitemporal hyperintensities, however, at that time clearly more marked within the right hemisphere.

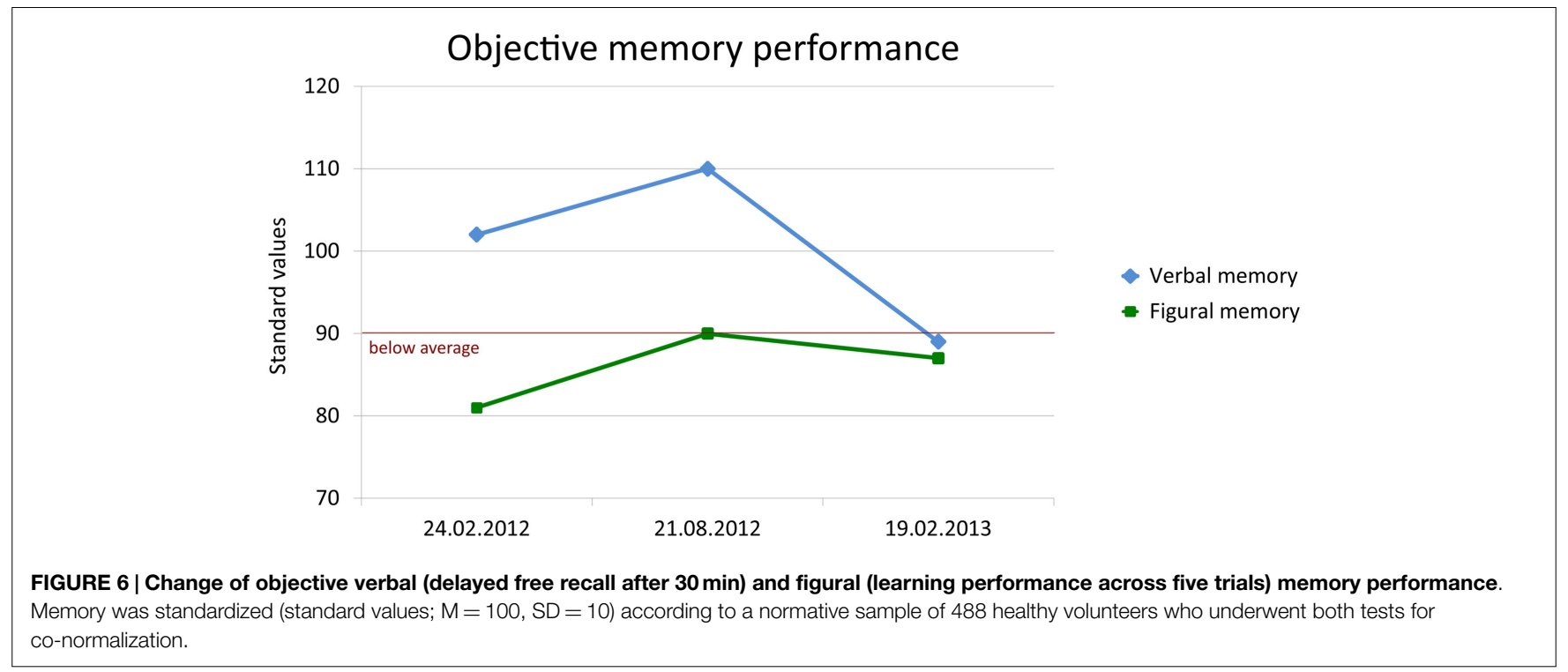


De Renzi and Lucchelli (24) describe a patient with hypoxic brain injury who suffered from severe retrograde amnesia, while learning of new information and delayed recall after $4 \mathrm{~h}$ was normal. After few days, however, the patient was no longer able to recall any aspect of the previously accessible memories. This reflects what has been recently termed accelerated long-term forgetting (25). In contrast to the case report by De Renzi and Lucchelli, most studies demonstrated accelerated long-term forgetting in patients with epilepsy, most of them suffering from complex partial seizures originating from the temporal lobe (26). In one case, accelerated long-term forgetting was observed in a patient with (paraneoplastic) limbic encephalitis with complex partial seizures (27). Parallel to the currently presented case report, this patient also reported a preceding behavioral change including depression and sleep abnormalities. Accelerated long-term forgetting has also been demonstrated in pediatric patients with idiopathic epilepsy $(28,29)$. The mechanism underlying accelerated long-term forgetting still remains obscure, but ictal and interictal epileptic activity as well as mesiotemporal pathologies have been discussed as etiological factors (25).

In the case report at hand, the reported subjective relief from accelerated long-term forgetting led to vast improvement in selfperceived memory, despite some deterioration in objective learning and memory functions (using standard retention intervals of $30 \mathrm{~min}$ ) at the final assessment (objective assessment of accelerated long-term forgetting was not performed again). Moreover, the reported subjective relief from anterograde accelerated

\section{References}

1. Bien CG, Elger CE. Limbic encephalitis: a cause of temporal lobe epilepsy with onset in adult life. Epilepsy Behav (2007) 10:529-38. doi:10.1016/j.yebeh.2007. 03.011

2. Bien CG, Urbach H, Schramm J, Soeder BM, Becker AJ, Voltz R, et al. Limbic encephalitis as a precipitating event in adult-onset temporal lobe epilepsy. Neurology (2007) 69:1236-44. doi:10.1212/01.wnl.0000276946.08412.ef

3. Vincent A, Bien CG, Irani SR, Waters P. Autoantibodies associated with diseases of the CNS: new developments and future challenges. Lancet Neurol (2011) 10:759-72. doi:10.1016/s1474-4422(11)70096-5

4. Correll CM. Antibodies in epilepsy. Curr Neurol Neurosci Rep (2013) 13:348. doi:10.1007/s11910-013-0348-1

5. Melzer N, Meuth SG, Wiendl H. Paraneoplastic and non-paraneoplastic autoimmunity to neurons in the central nervous system. J Neurol (2013) 260:1215-33. doi:10.1007/s00415-012-6657-5

6. Malter MP, Helmstaedter C, Urbach H, Vincent A, Bien CG. Antibodies to glutamic acid decarboxylase define a form of limbic encephalitis. Ann Neurol (2010) 67:470-8. doi:10.1002/ana.21917

7. Helmstaedter C, Pohl C, Hufnagel A, Elger CE. Visual learning deficits in nonresected patients with right temporal lobe epilepsy. Cortex (1991) 27:547-55. doi:10.1016/S0010-9452(13)80004-4

8. Helmstaedter C, Lendt M, Lux S. (2001). VLMT Verbaler Lern- und Merkfähigkeitstest. Göttingen: Beltz Test GmbH.

9. Helmstaedter C. EpiTrack. Veränderungssensitives kognitives Screening zur Qualitäts- und Outcomekontrolle der medikamentösen Epilepsiebehandlung. Monheim: UCB-Pharma (2012).

10. Gleissner U, Helmstaedter C, Elger CE. Right hippocampal contribution to visual memory: a presurgical and postsurgical study in patients with temporal lobe epilepsy. J Neurol Neurosurg Psychiatry (1998) 65:665-9. doi:10.1136/jnnp. 65.5.665

11. Witt J-A, Coras R, Schramm J, Becker AJ, Elger CE, Blümcke I, et al. The overall pathological status of the left hippocampus determines preoperative verbal memory performance in left mesial temporal lobe epilepsy. Hippocampus (2014) 24:446-54. doi:10.1002/hipo.22238 long-term forgetting was accompanied by partial recovery of retrograde autobiographical memory. This points to a partly reversible access problem to recent episodic memories rather than permanent memory loss. In this regard, a role of the active inflammatory process can be assumed beyond the hypothesized effects of epileptic activity.

\section{Conclusion}

Amygdala swelling, retrograde autobiographic memory loss, accelerated long-term forgetting, and emotional instability may serve as indicators of limbic encephalitis even in the absence of overt epileptic seizures. The monitoring of such patients calls for a standardized and concerted multilevel diagnostic approach with repeated assessments. Cognitive and behavioral problems in limbic encephalitis seem to originate from the complex interplay of active inflammation, structural changes, and epileptic dysfunction/seizures, and they appear (in part) reversible when the disease is successfully treated.

\section{Author Contributions}

All authors conceptualized the study. JAW drafted the manuscript. JAW, VLV, GW, and KJL provided figures. All authors revised and extended the manuscript, and approved its final version. All authors agree to be accountable for all aspects of the work.

12. Fernández G, De Greiff A, Von Oertzen J, Reuber M, Lun S, Klaver P, et al. Language mapping in less than 15 minutes: real-time functional MRI during routine clinical investigation. Neuroimage (2001) 14:585-94. doi:10.1006/nimg. 2001.0854

13. Witt J-A, Prömpler K, Maydych V, Helmstaedter C. Cross-validation of the animation description paradigm applied to determine language dominance via functional transcranial Doppler sonography. Epilepsy Behav (2010) 17:611-611. doi:10.1016/j.yebeh.2010.01.134

14. Witt J-A, Glöckner C, Helmstaedter C. Extended retention intervals can help to bridge the gap between subjective and objective memory impairment. Seizure (2012) 21:134-40. doi:10.1016/j.seizure.2011.10.007

15. Geisler S, Willuweit A, Schroeter M, Zilles K, Hamacher K, Galldiks N, et al. Detection of remote neuronal reactions in the thalamus and hippocampus induced by rat glioma using the PET tracer cis-4- $\left[{ }^{18} \mathrm{~F}\right]$ fluoro-D-proline. J Cereb Blood Flow Metab (2013) 33:724-31. doi:10.1038/jcbfm.2013.8

16. Geisler S, Ermert J, Stoffels G, Willuweit A, Galldiks N, Filss CP, et al. Isomers of 4-[18F]fluoro-proline: radiosynthesis, biological evaluation and results in humans using PET. Curr Radiopharm (2014) 7:123-32. doi:10.2174/ 1874471007666140902152916

17. Markowitsch HJ, Staniloiu A. Amygdala in action: relaying biological and social significance to autobiographical memory. Neuropsychologia (2011) 49:718-33. doi:10.1016/j.neuropsychologia.2010.10.007

18. Wagner J, Witt J-A, Helmstaedter C, Malter MP, Weber B, Elger CE. Automated volumetry of the mesiotemporal structures in antibody-associated limbic encephalitis. J Neurol Neurosurg Psychiatry (2014). doi:10.1136/ jnnp-2014-307875

19. Bak TH, Antoun N, Balan KK, Hodges JR. Memory lost, memory regained: neuropsychological findings and neuroimaging in two cases of paraneoplastic limbic encephalitis with radically different outcomes. J Neurol Neurosurg Psychiatry (2001) 71:40-7. doi:10.1136/jnnp.71.1.40

20. Hirayama K, Taguchi Y, Sato M, Tsukamoto T. Limbic encephalitis presenting with topographical disorientation and amnesia. J Neurol Neurosurg Psychiatry (2003) 74:110-2. doi:10.1136/jnnp.74.1.110

21. Chan D, Henley SMD, Rossor MN, Warrington EK. Extensive and temporally ungraded retrograde amnesia in encephalitis associated with antibodies to 
voltage-gated potassium channels. Arch Neurol (2007) 64:404-10. doi:10.1001/ archneur.64.3.404

22. Kataoka H, Furiya Y, Ueno S. Limbic encephalitis with involvement of prefrontal cortices and persistent amnesia. Neurologist (2008) 14:255-7. doi:10. 1097/NRL.0b013e31816b73fe

23. Kartsounis LD, De Silva R. Unusual amnesia in a patient with VGKC-Ab limbic encephalitis: a case study. Cortex (2011) 47:451-9. doi:10.1016/j.cortex. 2010.01.009

24. De Renzi E, Lucchelli F. Dense retrograde amnesia, intact learning capability and abnormal forgetting rate: a consolidation deficit? Cortex (1993) 29:449-66. doi:10.1016/S0010-9452(13)80253-5

25. Butler CR, Zeman AZ. Recent insights into the impairment of memory in epilepsy: transient epileptic amnesia, accelerated long-term forgetting and remote memory impairment. Brain (2008) 131:2243-63. doi:10.1093/brain/ awn 127

26. Elliott G, Isaac CL, Muhlert N. Measuring forgetting: a critical review of accelerated long-term forgetting studies. Cortex (2014) 54:16-32. doi:10.1016/ j.cortex.2014.02.001

27. O'connor M, Sieggreen MA, Ahern G, Schomer D, Mesulam M. Accelerated forgetting in association with temporal lobe epilepsy and paraneoplastic encephalitis. Brain Cogn (1997) 35:71-84. doi:10.1006/brcg. 1997.0928

28. Davidson M, Dorris L, O'regan M, Zuberi SM. Memory consolidation and accelerated forgetting in children with idiopathic generalized epilepsy. Epilepsy Behav (2007) 11:394-400. doi:10.1016/j.yebeh.2007.05.004

29. Gascoigne MB, Barton B, Webster R, Gill D, Antony J, Lah SS. Accelerated long-term forgetting in children with idiopathic generalized epilepsy. Epilepsia (2012) 53:2135-40. doi:10.1111/j.1528-1167.2012.03719.x

Conflict of Interest Statement: Juri-Alexander Witt, Viola Lara Vogt, Guido Widman, Karl-Josef Langen, Christian Erich Elger, and Christoph Helmstaedter report no conflicts of interest.

Copyright (C) 2015 Witt, Vogt, Widman, Langen, Elger and Helmstaedter. This is an open-access article distributed under the terms of the Creative Commons Attribution License (CC BY). The use, distribution or reproduction in other forums is permitted, provided the original author(s) or licensor are credited and that the original publication in this journal is cited, in accordance with accepted academic practice. No use, distribution or reproduction is permitted which does not comply with these terms. 